\title{
A carbon-doped tantalum dioxyfluoride as a superior electron transport material for high performance organic optoelectronics
}

Maria Vasilopoulou, ${ }^{a,}$ Abd Rashid Bin Mohd Yusoff, ${ }^{b}$ Navaratnarajah Kuganathan, ${ }^{c, d}$ Xichang Bao, ${ }^{e}$ Apostolis Verykios, ${ }^{a, f}$ Ermioni Polydorou, ${ }^{a, f}$ Konstantina-Kalliopi Armadorou, ${ }^{a, g}$ Anastasia Soultati, ${ }^{a}$ Georgios Papadimitropoulos, ${ }^{a}$ Muhammad Irfan Haider, ${ }^{\mathrm{h}, \mathrm{i}}$ Azhar Fakharuddin,,${ }^{\mathrm{h}, \mathrm{j}}$ Leonidas C. Palilis, ${ }^{f}$ Stella Kennou, ${ }^{k}$ Alexander Chroneos,${ }^{c, d}$ Panagiotis Argitis, ${ }^{a}$ Dimitris Davazoglou ${ }^{a}$

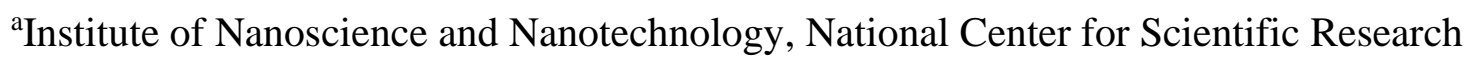
“Demokritos”, 15341 Agia Paraskevi, Attica, Greece. *E-mail: m.vasilopoulou@inn.demokritos.gr ${ }^{\mathrm{b}}$ Advanced Display Research Center, Department of Information Display, Kyung Hee University, 130-701 Seoul, South Korea.

'Department of Materials, Imperial College London, London SW7 2AZ, UK

${ }^{\mathrm{d}}$ Faculty of Engineering, Environment and Computing, Coventry University, Priory Street, Coventry CV1 5FB, United Kingdom

${ }^{\text {e}}$ Qingdao Institute of Bioenergy and Bioprocess Technology, Chinese Academy of Sciences, Qingdao 266101, China

fDepartment of Physics, University of Patras, 26504 Patras, Greece

gDepartment of Chemistry, National and Kapodestrian University of Athens, 15771, Zografos, Greece

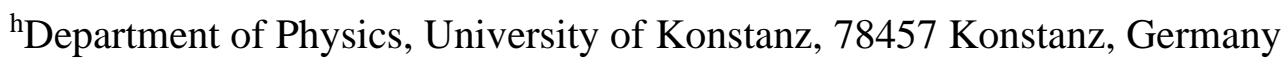

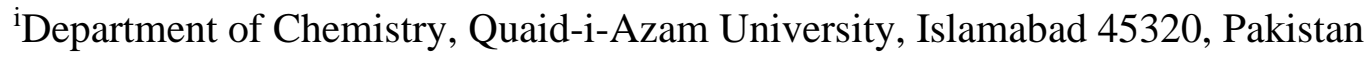
${ }^{\mathrm{j}}$ IMEC Kapeldreef 75, Heverlee 3001, Belgium (present affiliation)

${ }^{k}$ Department of Chemical Engineering, University of Patras, 26504 Patras, Greece 


\begin{abstract}
The design and development of novel materials with superior charge transport capabilities plays an essential role for advancing the performance of electronic devices. Ternary and doped oxides can be potentially explored because of their tailored electronic energy levels, exceptional physical properties, high electrical conductivity, excellent robustness and enhanced chemical stability. Here, a route for improving metal oxide characteristics is proposed by engineering a novel ternary oxide, namely, carbon-doped tantalum dioxyfluoride $\left(\mathrm{TaO}_{2} \mathrm{FC}_{\mathrm{x}}\right)$ through a straightforward synthetic route and exploring its effectiveness as an electron transport material in optoelectronic devices based on organic semiconductors. We fabricated fluorescent green organic light emitting diodes with current efficiencies of $16.53 \mathrm{~cd} / \mathrm{A}$ and single-junction non-fullerene organic solar cells reaching power conversion efficiencies of $14.14 \%$ when using the novel oxide as electron transport material outperforming the devices with the commonly used ones (such as zinc oxide). Our devices also exhibited the additional advantage of high operational and temporal stability. Non-fullerene OSCs based on the novel compound show unprecedented stability when exposed to UV light in air due to the non-defective nature of $\mathrm{TaO}_{2} \mathrm{FC}_{\mathrm{x}}$. We employed a tank of experiments combined with theoretical calculations to unravel the performance merits of this novel compound. This study reveals that properly engineered ternary oxides and in particular $\mathrm{TaO}_{2} \mathrm{FC}_{\mathrm{x}}$ or analogous materials can enable efficient electron transport in organic optoelectronics and it is proposed as an attractive route for the broader field of optoelectronic devices including halide organic-inorganic perovskite, colloidal quantum dot and Si optoelectronics.
\end{abstract}

\title{
1. Introduction
}

Optoelectronic devices using solution-processed semiconductors, such as organic semiconductors and halide organic-inorganic perovskites, are the frontrunners in near future applications on the areas of solid-state lighting and solar energy exploration due to their low cost and enhanced performance [1,2]. 
Solution-processable organic semiconductor-based devices, such as organic light emitting diodes (OLEDs) and organic solar cells (OSCs), continue to draw large interest due to their high stability and non-toxicity $[3,4]$. These, combined with the renaissance OSCs witnessed in recent years in terms of their performance make them a competitive choice for real-life applications. The progress in OLEDs and OSCs has been mainly accomplished by the development of novel semiconductors such as nonfullerene acceptors and more advanced device architectures [5-9]. Their market entry, however, requires further improvements in efficiency and, more importantly, a longer operational stability. A critical aspect towards enhanced device performance is the carrier injection/transport efficiency of the electrodes to/from the emitter/absorber organic materials. Particularly, the electron transport layer (ETL) is indispensable for achieving high electron transfer rates to/from the cathode electrode and maximising the device efficiency [10,11]. Besides appropriate energy levels to form a type II (i.e. staggered gap) heterojunction with the organic semiconductor, an ideal ETL must also possess an adequate n-type conductivity, a low refractive index to enhance the out-coupling efficiency (in LEDs), robustness, high hydrophobicity to restrict water adsorption on the organic semiconductor surface and prolong device stability $[12,13]$. In devices with regular (i.e. $\mathrm{p}-\mathrm{i}-\mathrm{n}$ ) architecture, the latter is highly crucial to avoid moisture penetration into the active organic layer before cathode deposition. Various types of electron transport materials, such as alkali-earth metals [14], polyamine compounds [15], polyelectrolytes [16], poly(ionic liquids) [17], and metal salts and bases [18], have been developed. Remarkably, research on the intrinsically robust and environmental stable inorganic transition-metal oxides as ETLs in organic and related perovskite optoelectronics is scarce although there are more than 4,000 ternary metal oxides catalogued in the Inorganic Crystal Structure Database (ICSD). Highly defective zinc oxide $(\mathrm{ZnO})$, titanium dioxide $\left(\mathrm{TiO}_{2}\right)$ and the less-defective tin oxide $\left(\mathrm{SnO}_{2}\right)$ are the most employed metal oxides (in pristine form and doped) reported so far [19-21]. The former both are known to induce degradation due to chemical reaction at their interface with organic/perovskite layer thereby making them not suitable for long-term stable devices [22]. Recently, some alternative ternary 
oxides such as the La-doped $\mathrm{BaSnO}_{3}$ [23], and the $\mathrm{PbZrTiO}_{3}$ ferroelectric oxide [24], have been successfully applied as electron extraction materials in perovskite solar cells. However, future optoelectronic devices targeting technological applications urgently require the extensive exploration of next generation of metal oxide-based charge transport interlayers to simultaneously enhance stability and device efficiency [25].

Tantalum pentoxide $\left(\mathrm{Ta}_{2} \mathrm{O}_{5}\right)$ is a non-defective wide bandgap material with a large refractive index, high thermal and chemical stability under various environments. It has attracted considerable attention as a high dielectric constant gate oxide for field-effect transistors and resistive memories and in coating and photocatalytic fields [26]. However, the large optical bandgap (larger than $4.0 \mathrm{eV}$ ) and extremely poor electrical conductivity render stoichiometric render $\mathrm{Ta}_{2} \mathrm{O}_{5}$ highly unsuitable as charge transport material for applications, such as in solar energy to electricity conversion and solid-state lighting. Wan et al. reported that $\mathrm{Ta}$ sub-oxide $\left(\mathrm{TaO}_{\mathrm{x}}\right)$ is a promising electron selective contact for crystalline $\mathrm{Si}$ photovoltaics and photo-electrochemical water reduction [27]. Tantalum oxynitride (TaON) [28], dioxychloride $\left(\mathrm{TaO}_{2} \mathrm{Cl}\right)$ [29], and dioxyfluoride $\left(\mathrm{TaO}_{2} \mathrm{~F}\right)$ [30], and the $\mathrm{MXene}$ family member tantalum hemicarbide $\left(\mathrm{Ta}_{2} \mathrm{C}\right)$ [31], are excellent electrocatalysts for several catalytic reactions because of their suitable optical bandgap and superior charge transfer rates. Among these electrocatalysts, $\mathrm{TaO}_{2} \mathrm{~F}$ is the most stable inorganic compound found in nature because it exhibits the highest known melting points of all existing materials [30,32]. Furthermore, carbon (C) doping has been proven to improve the stability and the light harvesting and charge separation efficiency of many compounds possessing photocatalytic activity $[33,34]$. These motivated us to design and develop a novel ternary compound with exceptional physical and electronic properties. The novel carbon-doped tantalum dioxyfluoride $\left(\mathrm{TaO}_{2} \mathrm{FC}_{\mathrm{x}}\right)$ exhibits well-matched energy levels with those of most organic semiconductors, high electron conductivity, extremely low refractive index and high hydrophobicity, therefore representing an ideal choice for the cathode interface for several types of optoelectronic devices. As a proof of concept, we apply our novel compound in OLEDs and OSCs with diverse architectures. 


\section{Experimental Section}

Preparation of $\mathrm{TaO}_{2} \mathrm{FCx}$. $\mathrm{TaO}_{2} \mathrm{FC}_{\mathrm{x}}$ films were deposited in a MOCVD reactor by using $\mathrm{TaO}_{\mathrm{x}}$ and $\mathrm{C}_{3} \mathrm{~F}_{6} \mathrm{O}$ (purchased from Sigma-Aldrich) vapours. $\mathrm{TaO}_{\mathrm{x}}$ vapours were produced by heating a superficially oxidised metallic (Ta) filament (purchased from Merck) at $1000{ }^{\circ} \mathrm{C}$. The $\mathrm{C}_{3} \mathrm{~F}_{6} \mathrm{O}$ vapour was introduced in the deposition chamber by $(10 \mathrm{sccm}) \mathrm{N}_{2}$ stream bubbling through a saturator maintained at $60{ }^{\circ} \mathrm{C}$. For the deposition, substrates were loaded on a copper susceptor (fixed between two $\mathrm{Cu}$ current leads) located $5 \mathrm{~cm}$ below the filament. The chamber was evacuated to $10^{-2}$ Torr, and the gases were inserted (flow of $100 \mathrm{sccm}$ of $\mathrm{N}_{2}$ and $\mathrm{C}_{3} \mathrm{~F}_{6} \mathrm{O}$ vapours), followed by automatic pressure stabilisation to 1 Torr with the aid of a pressure control system consisting of a baratron manometer and an automatically driven butterfly valve. Finally, the filament was heated with the application of an AC $(50 \mathrm{~Hz})$ current to produce the $\mathrm{TaO}_{\mathrm{x}}$ vapors. Bias voltage and deposition time were used to control film thickness with time varying between 1 and $60 \mathrm{~s}$. The deposition of a pristine $\mathrm{TaO}_{\mathrm{x}}$ was performed in a $\mathrm{N}_{2}$ environment without the introduction of $\mathrm{C}_{3} \mathrm{~F}_{6} \mathrm{O}$ vapours inside the chamber. During deposition, the substrate was near room temperature.

Theoretical methodology. All calculations were performed using dispersion corrected density functional theory as implemented in the VASP code, which solves the standard Kohn-Sham equations by using plane wave basis sets. For the exchange correlation energy term, the generalised gradient approximation was used in the form of the PBEsol functional. The standard projected augmented wave potentials and a plane-wave basis set with a cut off value of $500 \mathrm{eV}$ were employed. A $4 \times 2 \times 4$ Monkhorst-Pack $k$ point mesh, which yielded $20 k$ points, was used in all calculations. The valence electronic configurations for Ta, $\mathrm{O}$ and $\mathrm{F}$ were $5 \mathrm{p}^{6} 6 \mathrm{~s}^{2} 5 \mathrm{~d}^{3}, 2 \mathrm{~s}^{2} 2 \mathrm{p}^{4}$ and $2 \mathrm{~s}^{2} 2 \mathrm{p}^{5}$, respectively. Structural optimisations were performed using a conjugate gradient algorithm, and the forces on the atoms were obtained from the Hellmann-Feynman theorem, including Pulay corrections. In all optimised structures, forces on the atoms were smaller than $0.001 \mathrm{eV} / \AA$. In this work, dispersion was included using the pair-wise force field, as implemented by Grimme et al. in the VASP package [35]. 
OLED device preparation and characterization. OLEDs were fabricated on ITO coated glass substrates (with a sheet resistance of $20 \Omega / \mathrm{sq}$ ), which served as the anode electrode. Prior to the polymer semiconductors' deposition, the substrates were sequentially sonicated in acetone, 2-propanol and DI water for $10 \mathrm{~min}$ and then dried in a $\mathrm{N}$ flow. The substrates were then treated with $\mathrm{O}$ plasma for $10 \mathrm{~min}$, followed by spin-coating of a thin $(\sim 40 \mathrm{~nm})$ layer of PEDOT-PSS (1.3 wt.\% dispersion in $\mathrm{H}_{2} \mathrm{O}$ filtered with a $0.45 \mu \mathrm{m}$ PVDF filter) (purchased from Sigma Aldrich) in ambient conditions at $7000 \mathrm{rpm}$ for $40 \mathrm{~s}$. PEDOT:PSS was annealed at $130{ }^{\circ} \mathrm{C}$ for $30 \mathrm{~min}$ to remove water. The emissive layer (F8BT, 9:1 F8:BT ratio, purchased from American Dye Source, ADS 233 YE) was then spin coated onto PEDOT-PSS from a $10 \mathrm{mg} \mathrm{mL}^{-1}$ chloroform solution (filtered through a $0.22 \mu \mathrm{m}$ PTFE filter) at $1200 \mathrm{rpm}$ for $40 \mathrm{~s}$ to form a $70 \mathrm{~nm}$ layer. The F8BT film was then annealed at $95{ }^{\circ} \mathrm{C}$ for 10 min to improve its morphology. In the control OLEDs, a thin $\mathrm{Cs}_{2} \mathrm{CO}_{3}$ layer was instead deposited onto F8BT by spin coating at $2000 \mathrm{rpm}$ for $40 \mathrm{~s}$ from a $5 \mathrm{mg} \mathrm{mL}^{-1}$ methanol solution to act as the electron injection/transport layer. For the deposition of $\mathrm{TaO}_{2} \mathrm{FC}_{\mathrm{x}}$, some devices were transferred to a dedicated deposition chamber. The OLEDs' structure was completed with the deposition of a $150 \mathrm{~nm}$ aluminium cathode by using a shadow mask. The OLED characterization was previously described in details. ${ }^{47}$ OSC device fabrication and characterization. Regular architecture OSCs were fabricated on PEDOTPSS/ITO/glass substrates that were prepared with the protocol reported in the previous section. The substrates were subsequently transferred to an argon filled glove box for photoactive layer deposition. The PM6F:IT-4F (both purchased from Ossila) blend was dissolved in chlorobenzene (CB) at a concentration of $20 \mathrm{mg} / \mathrm{ml}\left(1: 1\right.$ weight ratio) and stirred at $40{ }^{\circ} \mathrm{C}$ for $3 \mathrm{~h}$. Prior to spin coating, 1,8 iodooctane (DIO) $(0.6 \%, \mathrm{v} / \mathrm{v})$ was added to the solution. Films were spin coated at $1700 \mathrm{rpm}$ for $60 \mathrm{~s}$ and then annealed at $100{ }^{\circ} \mathrm{C}$ for $10 \mathrm{~min}$. The PTB7-Th:PC $71 \mathrm{BM}$ blend (both purchased from Ossila) was dissolved in 1,2 diCB (o-DCB) at a concentration of $25 \mathrm{mg} / \mathrm{ml}(1: 1.5$ weight ratio) and stirred at $60{ }^{\circ} \mathrm{C}$ for $3 \mathrm{~h}$. Prior to spin-coating, DIO (3\%, v/v) was added to the solution. PTB7-Th:PC 71 BM films were spin coated at $1000 \mathrm{rpm}$ for $90 \mathrm{~s}$ and left to dry for $30 \mathrm{~min}$. The control samples were modified 
with a PDINO ETL that was spin coated from a $5 \mathrm{mg} / \mathrm{ml}$ methanol at $2000 \mathrm{rpm}$ for $40 \mathrm{~s}$, whereas the samples with $\mathrm{TaO}_{2} \mathrm{FC}_{\mathrm{x}}$ were immediately transferred from the glove box to the dedicated deposition chamber. OSCs were completed with the thermal evaporation of an Al electrode with a shadow mask defining the active cell area. For the inverted architecture OSCs, a $30 \mathrm{~nm}$-thick ETL was deposited on pre-cleaned and $\mathrm{O}_{2}$ plasma-treated FTO substrates. A ZnO ETL was formed by spin-coating from a $0.5 \mathrm{~mol} / \mathrm{L} \mathrm{ZnC} \mathrm{ZH}_{6} \mathrm{O}_{4}$ solution in ethanolamine and 2-methoxyethanol, which was then heated at $200{ }^{\circ} \mathrm{C}$ for $30 \mathrm{~min}$. The $\mathrm{TaO}_{2} \mathrm{FC}_{\mathrm{x}}$ layer was deposited as described above, followed by the deposition of the PM6:IT-4F blend and $10 \mathrm{~nm}$-thick $\mathrm{MoO}_{\mathrm{x}}$ capped with a $150 \mathrm{~nm} \mathrm{Al}$ anode. The device active area was $0.13 \mathrm{~cm}^{2}$. The cell active area was fixed at $12.56 \mathrm{~mm}^{2}$ by the use of a shadow mask. Solar cell optoelectronic characterization was performed as reported elsewhere [36,37].

Electron mobility calculations. For the calculations of the electron mobility of both the PM6:IT-4F and PTB7-Th:PC ${ }_{71} \mathrm{BM}$ blends in fabricated electron-only devices, and the $\mathrm{J}-\mathrm{V}$ characteristics were fitted in the space charge limited conduction regime with the Mott-Gurney law, including the Frenkel effect on the electric field dependent mobility, as given by the equation:

$$
\mathrm{J}=(9 / 8) \varepsilon_{0} \varepsilon_{\mathrm{r}} \mu_{0} \exp \left[0,89 \beta\left\{(\mathrm{V} / \mathrm{d}\}^{1 / 2}\right]\left(\mathrm{V}^{2}\right) /\left(\mathrm{d}^{3}\right), \quad \text { (equation } 1\right)
$$

For current density $\mathrm{J}$, applied voltage $\mathrm{V}$, free space permittivity $\varepsilon_{0}$, relative blend permittivity $\varepsilon_{\mathrm{r}}$ $\left(e_{r}=3.5\right)$, zero-field electron mobility $\mu_{0}$, field activation factor $\beta$ and active layer thickness $d(d=120$ $\mathrm{nm})$. The fitting parameters $\mu_{0}$ and $\beta$ are listed in Tables S4 and S6, respectively, and were extracted from the intercept and slope of the J vs. $\mathrm{V}^{1 / 2}$ plot.

Additional characterization. XPS and UPS measurements characterised the surface chemical composition and the electronic structure of $\mathrm{TaO}_{2} \mathrm{FC}_{\mathrm{x}}$ films deposited on ITO/glass or on an F8BT coated glass substrate. An unmonochromatised Mg Ka line at $1253.6 \mathrm{eV}$ (12 keV with $15 \mathrm{~mA}$ anode current) and an analyser (Leybold EA-11) pass energy of $100 \mathrm{eV}$, which gives a full width at half maximum of $1.3 \mathrm{eV}$ for the $\mathrm{Au} 4 \mathrm{f}_{7 / 2}$ peak, were used for the XPS measurements, whereas XPS analysis was performed at $0^{\circ}$ take-off angle. In all XPS spectra the BE of the predominant aliphatic contribution 
to the $\mathrm{C} 1 \mathrm{~s}$ peak at $284.8 \mathrm{eV}$ was used as a measured $\mathrm{BE}$ reference. The analysed area was approximately a $2 \times 5 \mathrm{~mm}^{2}$ rectangle positioned near the geometric centre of each sample. The UPS measurements (that was taken first followed by XPS measurements) were performed using the He I $(21.2 \mathrm{eV})$ excitation line, and a voltage of $12.23 \mathrm{~V}$ that was applied to the specimen to separate the high BE cut-off from the analyser. The composition and crystallinity of ternary oxide films was studied with an X-ray Siemens D-500 diffractometer. UV-Vis transmittance/absorption measurements were recorded using a Perkin Elmer Lambda 40 UV/Vis spectrometer. The surface topographies/morphologies were prompted with NT-MDT AFM and a JEOL 7401f FESEM.

\section{Results and discussion}

Figure 1a illustrates the preparation of the ternary compound. Tantalum oxide $\left(\mathrm{TaO}_{\mathrm{x}}\right)$ vapours were produced by heating a superficially oxidised tantalum filament, which were reacted with hexafluoroacetone $\left(\mathrm{C}_{3} \mathrm{~F}_{6} \mathrm{O}\right)$ vapours introduced inside the deposition chamber by bubbling of a nitrogen $\left(\mathrm{N}_{2}\right)$ stream through a saturator kept at $60{ }^{\circ} \mathrm{C}$. The ternary material was deposited as a thin film on top of selected substrates at room temperature. X-ray (XPS) and ultra-violet (UPS) photoelectron spectroscopies were employed to reveal the chemical composition (i.e. stoichiometry), valence band $(\mathrm{VB})$ position and work function $\left(\mathrm{W}_{\mathrm{F}}\right)$ of the material, which are all highly critical to its application as an electron selective layer. Figure 1b depicts the Ta 4f XPS core levels, which consist of two different doublet peaks attributed to Ta $4 \mathrm{f}_{7 / 2}$ and $\mathrm{Ta} 4 \mathrm{f}_{5 / 2}$. In the first doublet, the Ta $4 \mathrm{f}_{7 / 2}$ peaks at $26.2 \mathrm{eV}$ and is attributed to the stoichiometric oxide phase [38]. The second doublet is shifted to high energies, and the $\mathrm{Ta} 4 \mathrm{f} 7 / 2$ appears at $26.9 \mathrm{eV}$ [39]. This doublet is assigned to a fluorinated oxide phase, and the shift to high energies is due to the high fluorine anion electronegativity [40]. The F 1s spectrum (Figure 1c) was fitted with two Gaussians peaked at 688.1 and $684.8 \mathrm{eV}$ attributed to fluorine anions bonded to Ta and C, respectively [41,42]. This finding indicates the incorporation of C within the structure of the developed material. The O 1s spectrum (Figure 1d) was also fitted with two 
Gaussians, one peaked at 530.6, which is attributed to Ta-O bonds, and a second peaked at $531.7 \mathrm{eV}$, which is attributed to $-\mathrm{OH}$ groups due to surface contamination. Figure 1e depicts the high binding energy cut-off region (left), the full VB (middle) and the near Fermi level region (right) of the UPS spectrum of $\mathrm{TaO}_{2} \mathrm{FC}_{\mathrm{x}}$. The $\mathrm{VB}$ maximum appears at $3.0 \mathrm{eV}$ below the Fermi level, whereas the $\mathrm{W}_{\mathrm{F}}$ is $4.3 \mathrm{eV}$. No defect bands appear inside the band gap, suggesting that the synthesised material is nondefective. The material also exhibits a lower bandgap than the pristine $\mathrm{TaO}_{\mathrm{x}}$ deposited in an $\mathrm{O}$ environment (Figure S1a and S2a, Supporting Information); however, the former is highly transparent (Figure S1b), which is highly desirable during application at the bottom cathode electrode of inverted devices. In the X-ray diffraction pattern (Figure 1f), three crystalline peaks appear at $2 \theta$ the positions of $33^{\circ}, 62^{\circ}$ and $65^{\circ}$. These peaks are characteristic of $\mathrm{TaO}_{2} \mathrm{~F}[43,44]$. The $\mathrm{TaO}_{\mathrm{x}}$ deposited without the injection of $\mathrm{C}_{3} \mathrm{~F}_{6} \mathrm{O}$ is completely amorphous (Figure S3). Additionally, the material exhibits an extremely low refractive index of approximately 1.3 in the visible and near-IR region (Figure $1 \mathrm{~g}$ ), which is attributed to its high fluorine content [45]. The refractive index of the pristine oxide is approximately 2.0 (Figure S4) according to literature [46]. The surface topography of the ternary compound is grain-like (Figure 1h) with the grain size, thickness (Figure S5), porosity (Figure S6) and surface roughness (Figure S7) precisely controlled by changing the deposition environment, bias voltage applied on the Ta wire and deposition time. These changes, however, do not significantly impact on the stoichiometry (Figure S8 and S9), thus offering a large window for potential material applications that require either a compact thin layer (i.e. organic) and related optoelectronics or a thick porous material (i.e. catalysis). High fluorine content also resulted in an increased hydrophobicity of the synthesized material (inset, Figure 1g), especially when compared to the pristine oxide (Figure S2b) thereby offering higher resilience to moisture attack. The developed material also exhibited an ntype conductivity of $1.26 \mathrm{~S} \mathrm{~cm}^{-1}$ (Figure 1i) whereas the pristine oxide was insulating (Figure 1i), as expected [47]. 
Theoretical calculations were also performed to reveal the properties of the developed material. The bulk structure of $\mathrm{TaO}_{2} \mathrm{~F}$ is cubic with space group of $P m \overline{3} \mathrm{~m}[43,48]$. The crystallographic refinement of $\mathrm{O} / \mathrm{F}$ ratio on the shared site is $0.6667: 0.3333$, implying a disordered composition (partially occupied) but maintained stoichiometry. Prior to examining the electronic structure and binding energies of a single gaseous $\mathrm{C}$ atom trapped in a $\mathrm{TaO}_{2} \mathrm{~F}$ lattice, a full occupancy model without modifying the overall composition was considered. Three possible models (Figure S10) were identified. The lattice energies of three structures were compared through the geometry optimisations of ion positions and cell parameters. Simulations determined that all three structures exhibit similar energies, suggesting that all three structures are identical. To consider the most favourable scenario of an interstitial $\mathrm{C}$ atom in the non-defective structure I, we generated a $3 \times 3 \times 3$ supercell consisting of 108 atoms. Figure S11 shows the relaxed supercell structure and its density of state (DOS) plot. Calculations revealed that bulk $\mathrm{TaO}_{2} \mathrm{~F}$ exhibits approximately $3.0 \mathrm{eV}$ band gap. Various possible interstitial positions were considered, and four promising relaxed structures were identified. Geometry-optimised structures together with a view of C interstitials are shown in Figure S12.

In the first configuration $(\mathrm{P}), \mathrm{C}$ is in the center of the cubic motif without forming remarkable bonds with $\mathrm{O}$ or $\mathrm{F}$ (Figure $\mathrm{S} 12$ ). This finding is reflected in the calculated bond distances and the almost zero Bader charge [49]. A small distortion in the lattice was observed. The binding energy is $-0.60 \mathrm{eV}$, suggesting that the $\mathrm{C}$ in this interstitial position is more stable than its isolated gaseous atom. Interstitial $\mathrm{C}$ introduces a peak at the top of the VB without altering the band gap, making this material nondefective as indicated by UPS. Charge density around C is shown in Figure 2. The second configuration (Q) consists of an interstitial $\mathrm{C}$ along the $b c$ plane with a notable interaction with $\mathrm{O}$ and $\mathrm{F}$ (Table S1 and Figure S12). This finding is also reflected in the Bader charge and relatively short bond distances. The interstitial $\mathrm{C}$ becomes slightly positive. The attractive interaction of $\mathrm{C}$ to $\mathrm{O}$ is slightly stronger compared with that to $\mathrm{F}$ based on the bond distances. The binding energy of $\mathrm{C}$ for the formation of this configuration is $-0.20 \mathrm{eV}$, which is less favourable than that of configuration P. However, an important 
binding was observed in configuration $\mathrm{R}$. In this configuration, $\mathrm{C}$ forms four short bonds with $\mathrm{O}$ and lies on the $a c$ plane. On the contrary, $\mathrm{F}$ is further away from $\mathrm{C}$, and its interaction with $\mathrm{C}$ is weak as observed in the $\mathrm{C}-\mathrm{F}$ distances. Binding energy is $-1.15 \mathrm{eV}$, which is more exoergic than that observed in $\mathrm{P}$ and Q. Strong binding is reflected in the Bader charge (slightly more positive than that noted in $\mathrm{P}$ and Q) and charge density around $\mathrm{C}$ and its neighbouring atoms (Figure 2). The fourth configuration (S) exhibits the strongest interaction between $\mathrm{C}$ and $\mathrm{O}$ in the lattice. The binding energy is $-5.89 \mathrm{eV}$, indicating a significant interaction with the lattice. Figure S12 shows the strong bonding interaction between $\mathrm{C}$ and $\mathrm{O}$. This finding is reflected in the shortest $\mathrm{C}-\mathrm{O}$ bond distance $(1.29 \AA)$. A distortion in the lattice with F atoms moving slightly further away was observed. DOS and atomic DOS plots clearly show that the peak introduced by $\mathrm{C}$ is now mixed with the VB. Strong bonding interaction is also reflected in the charge density plot.

To explore the potential applicability of the novel compound in optoelectronic devices we then deposited a $6 \mathrm{~nm}$-thick $\mathrm{TaO}_{2} \mathrm{FC}_{\mathrm{x}}$ film on top of the green emissive-conjugated copolymer semiconductor poly[(9,9-dioctylfluorenyl-2,7-diyl)-co-(1,4-benzo-2,1',3-thiadiazole)] (F8BT) (Figure S13) to evaluate its electron injection/transport capability in OLEDs. The alteration of the surface topography of F8BT (Figure S14) and the detection of Ta 4f XPS peaks on F8BT (Figure S15) indicate the successful deposition of the ternary compound on top of F8BT. The regular OLED configuration (Figure S16) consists of an indium $\mathrm{SnO}_{2}$ (ITO) layer as the transparent anode, a $40 \mathrm{~nm}$-thick poly(3,4ethylenedioxythiophene) polystyrene sulfonate (PEDOT-PSS) film as the hole transport layer, the emissive layer (F8BT or the blue emitting poly[2-(6-cyano-6'-methylheptyloxy)-1,4-phenylene] [CNPPP]) and aluminium cathode. In the reference devices, a commonly used $\mathrm{Cs}_{2} \mathrm{CO}_{3}$ film served as ETL for comparison. Figure S17 presents the energy level diagram of the materials used in the OLED structures that consider vacuum level alignment before contact. The VB and conduction band (CB) edges of $\mathrm{TaO}_{2} \mathrm{FC}_{\mathrm{x}}$ were estimated from UPS and absorption measurements, whereas the energy levels of the other OLED materials were obtained from literature [50]. The estimated CB value of 3.95 ( \pm 
0.1) $\mathrm{eV}$ for $\mathrm{TaO}_{2} \mathrm{FC}_{\mathrm{x}}$ is expected to be highly beneficial for electron transport because it is located between the lowest unoccupied molecular orbital (LUMO) of the emissive layers and the Al cathode $\mathrm{W}_{\mathrm{F}}$, thus forming a type II heterojunction with F8BT. Figure 3a presents the current density-voltageluminance $(\mathrm{J}-\mathrm{V}-\mathrm{L})$ characteristics of the F8BT-based OLEDs. Figure 3b, Figure S18 and Figure 3c show the current, power and external electroluminescence (EL) quantum efficiency of OLEDs versus the current density, respectively. Table S2 summarises the OLEDs performance characteristics, which are highly improved when $\mathrm{TaO}_{2} \mathrm{FC}_{\mathrm{x}}$ was incorporated as the ETL instead of $\mathrm{Cs}_{2} \mathrm{CO}_{3}[51]$. The $\mathrm{C}$-doped $\mathrm{TaO}_{2} \mathrm{~F}$-modified device exhibits an ultra-low turn-on voltage $(2.0 \mathrm{eV})$ that is even lower than that in the F8BT's bandgap (Figure S19), indicating a highly improved electron injection. This result was also proven by the current density-voltage (J-V) characteristics of electron-only devices (Figure S20). The achieved current efficiency of $16.53 \mathrm{~cd} / \mathrm{A}$ is one of the highest ever for OLEDs using a thin (approximately $70 \mathrm{~nm}$ ) F8BT layer [52,53]. The EL spectra are extremely similar to the photoluminescence emission spectrum of F8BT (Figure 3d and Figure S19a), suggesting that EL emission originates from the excitons that are generated exclusively inside F8BT. The hybrid oxide works as an effective ETL even in blue OLEDs (Figure S21) as evidenced by the CN-PPP emitter showing higher LUMO level than F8BT. As one of the major issues in OLEDs is their operational stability, we measured operational lifetime for both reference and $\mathrm{TaO}_{2} \mathrm{FC}_{\mathrm{x}}$-modified $\mathrm{F} 8 \mathrm{BT}$-based OLEDs in ambient. We note that whereas the reference device retained lower than $60 \%$ of its initial luminance after $100 \mathrm{~h}$ of continuous operation in air at $15 \mathrm{~mA} \mathrm{~cm}{ }^{-2}$ (Figure 3e, 3f), the device with the C-doped Ta dioxyfluoride ETL retained above $90 \%$ of its initial luminance. This is due to the superior quality of the modified cathode interface and its high robustness and hydrophobicity that act as a protective layer against moisture ingress into the device. UPS measurements obtained on a F8BT film prior to (Figure S22) and after the deposition of $\mathrm{TaO}_{2} \mathrm{FC}_{\mathrm{x}}$ on top (Figure 3g) revealed a remarkable decrease in the electron injection barrier from $1.1 \mathrm{eV}$ (Figure 3h) to $0.3 \mathrm{eV}$ (Figure 3i), which explains the superiority of the ternary compound as an electron injection/transport layer. This large reduction 
in the electron injection barrier enhances the electron injection/transport from the Al cathode to F8BT and improves the quality of the cathode interface; injection barriers $0-0.4 \mathrm{eV}$ indicate the formation of an Ohmic rather than a Schottky contact [54].

To explore the versatility of $\mathrm{TaO}_{2} \mathrm{FC}_{\mathrm{X}}$ in other organic optoelectronic devices, we fabricated single junction binary OSCs with the forward architecture. This employ blends of conjugated polymer donors with both fullerene (poly[4,8-bis(5-(2-ethylhexyl)thiophen-2-yl)benzo[1,2- $b$;4,5- $\left.b^{\prime}\right]$ dithiophene-2,6diyl-alt-(4-(2-ethylhexyl)-3-fluorothieno[3,4-b]thiophene-)-(2-carboxylate-2-6-diyl)]: $\quad$ phenyl-C $71^{-}$ butyric acid methyl ester, PTB7-Th:PC $\left.{ }_{71} \mathrm{BM}\right)$ and non-fullerene (poly[(2,6-(4,8-bis(5-(2-ethylhexyl-3fluoro)thiophen-2-yl)-benzo[1,2-b:4,5-b']dithiophene))-alt-(5,5-(1',3'-di-2-thienyl-5',7'-bis(2ethylhexyl)benzo[1',2'-c:4',5'-c']dithiophene-4,8-dione)]:3,9-bis(2-methylene-((3-(1,1dicyanomethylene)-6,7-difluoro)-indanone))-5,5,11,11-tetrakis(4-hexylphenyl)-dithieno[2,3-d:2',3'd']-s-indaceno[1,2-b:5,6-b']dithiophene, PM6:IT-4F) acceptors (Figure S23). The control devices included the well-established perylene diamide amino N-oxide (PDINO) as ETL on top of the photoactive blend. For the PTB7-Th:PC ${ }_{71} \mathrm{BM}$-based OSCs, a considerable improvement in power conversion efficiency (PCE) up to $10.48 \%$ was obtained by the $\mathrm{TaO}_{2} \mathrm{FC}_{\mathrm{x}}$-modified device compared with the reference device with the PDINO (PCE up to 9.40\%) (Figure S24 and Table S3). The enhanced OSC performance can be attributed to the high quality of the cathode contact as indicated by the low trap-assisted/mono-molecular recombination (Figure S23) and improved electron transport in the photoactive blend (Figure $\mathrm{S} 24$ and Table $\mathrm{S} 4$ ) of the $\mathrm{TaO}_{2} \mathrm{FC}_{\mathrm{x}}$-based device. In addition to the merits is the high long-term stability of the "self-encapsulated" $\mathrm{TaO}_{2} \mathrm{FC}_{\mathrm{x}}$-modified devices. This characteristic is directly related to the robustness and hydrophobic nature of the ternary material. The appropriate position of the $\mathrm{CB}$ edge of $\mathrm{TaO}_{2} \mathrm{FC}_{\mathrm{x}}$ facilitates electron extraction from the LUMO of $\mathrm{PC}_{71} \mathrm{BM}(\sim 3.9 \mathrm{eV})$ and the LUMOs of the recently developed non-fullerene acceptors $(\sim 4.0 \mathrm{eV})$ (Figure 4a) towards Al by acting as an intermediate energy step. As a result, the PM6:IT-4F based OSC with a regular architecture ITO/PEDOT-PSS/PM6:IT-4F/ETL/Al and the $\mathrm{TaO}_{2} \mathrm{FC}_{\mathrm{x}}$ as ETL reach 
a high maximum PCE of $13.18 \%$ (Figure $4 \mathrm{~b}$ and Table S5) and an average PCE of $12.77 \%$ (Figure 4c), indicating a remarkable enhancement relative to that of the control device with PDINO $\left(\mathrm{PCE}_{\max }=12.04 \%\right)$. The enhanced photon-to-electron conversion efficiency (Figure 4d) and improved electron transport (Figure 4e and Table S6 with the calculated electron mobilities) reveal the high quality of cathode interface in this device configuration. The incorporation of $\mathrm{TaO}_{2} \mathrm{FC}_{\mathrm{x}}$ also contributes to the excellent stability of the device when exposed to UV light under ambient conditions (Figure 4f). The performance is further enhanced in OSCs with the inverted architecture FTO/ETL (40 $\mathrm{nm}$ )/PM6:IT-4F/MoO $/ \mathrm{Al}$ using our developed material (or the widely used $\mathrm{ZnO}$ as reference) as the bottom ETL. The control device shows an inferior performance (reaching a maximum PCE of 13.03\%) compared with the $\mathrm{TaO}_{2} \mathrm{FC}_{\mathrm{x}}$ one $\left(\mathrm{PCE}_{\max }=14.14 \%\right)$ because of the advantages of the ternary material discussed above. This finding represents one of the high efficiencies of single junction PM6:IT-4Fbased OSCs currently reported [55,56]. The high UV-vis absorption of the PM6:IT-4F film on top of $\mathrm{TaO}_{2} \mathrm{FC}_{\mathrm{x}}$ (Figure S27) is assigned to the high transmittance (lower absorption) of the cathode contact, the absence of trap states on the surface of the ternary compound (Figure S28) and the improved nanomorphology of the photoactive layer due to the higher hydrophobicity of $\mathrm{TaO}_{2} \mathrm{FC}_{\mathrm{x}}$ compared with that of $\mathrm{ZnO}$ (Figure S29). All these observations verify the superior role of the $\mathrm{C}$-doped $\mathrm{TaO}_{2} \mathrm{~F}$ as an advanced electron transport material (Tables S8-S10) and open a new era for the application of nondefective oxide-based materials in optoelectronic devices.

\section{Conclusions}

In summary, we developed an efficient electron transport material for optoelectronic applications through simple and low-cost deposition. We incorporated the novel compound in fluorescent green OLEDs with current efficiencies of $16.53 \mathrm{~cd} / \mathrm{A}$ and non-fullerene OSCs reaching PCEs of $14.14 \%$ exhibited the additional advantage of high operational and temporal stability. Our methodology of $\mathrm{TaO}_{2} \mathrm{FC}_{\mathrm{x}}$ preparation can easily be extended to other simple and well-established deposition 
techniques, including solution-processing, to enable the low-cost development of C-doped metal oxyfluoride semiconductors. This study may open new avenues and create opportunities for research in organic materials, $\mathrm{Si}$, perovskite, quantum-dot solar cells and light-emitting devices.

\section{Acknowledgements}

High Performance Computing Centres at Imperial College London and Coventry University are acknowledged for rending computational facilities and support to run DFT calculations. X. B. thanks the Youth Innovation Promotion Association CAS (2016194) for financial support.

\section{Supporting Information}

Additional material and device characterization and theoretical calculations. 


\section{References}

1. Q. Wang, M. Nakabayashi, T. Hisatomi, S. Sun, S. Akiyama, Z. Wang, Z. Pan, X. Xiao, T. Watanabe, T. Yamada, N. Shibata, T. Takata, K. Domen, Oxysulfide photocatalyst for visiblelight-driven overall water splitting, Nat. Mater. 18 (2019) 827-832.

2. C. R. Bala, S. Breen, Y. Shao, S. Ardo, A. Z. Weber, Evaluating particle-suspension reactor designs for Z-scheme solar water splitting via transport and kinetic modeling, Energy Environ. Sci., 11 (2018) 115-135.

3. J. H. Burroughes, D. D. C. Bradley, A. R. Brown, R. N. Marks, K. Mackay, R. H. Friend, P. L. Burns, A. B. Holmes, Light-emitting diodes based on conjugated polymers, Nature 347 (1990) $539-541$.

4. S. R. Forrest, The path to ubiquitous and low-cost organic electronic appliances on plastic, Nature 428 (2004) 911-918.

5. Z. He, B. Xiao, F. Liu, H. Wu, Y. Yang, S. Xiao, C. Wang, T. P. Russell, Y. Cao, Single-junction polymer solar cells with high efficiency and photovoltage, Nat. Photonics 9 (2015) 174-179.

6. G. Li, R. Zhu, Y. Yang, Y. Polymer solar cells. Nat. Photonics 6 (2012) 153-161.

7. C.-C. Chueh, C.-Z. Li, A. K. Y. Jen, Recent progress and perspective in solution-processed interfacial materials for efficient and stable polymer and organometal perovskite solar cells, Energy Environ. Sci. 8 (2015) 1160-1189.

8. F. Wang, Z. A. Tan, Y. Li, Solution-processable metal oxides/chelates as electrode buffer layers for efficient and stable polymer solar cells, Energy Environ. Sci. 8 (2015) 1059-1091.

9. Z. Yin, J. Wei, Q. Zheng, Interfacial materials for organic solar cells: Recent advances and perspectives, Adv. Sci. 3 (2016) 1500362.

10. Y. Zhou, C. Fuentes-Hernandez, J. Shim, J. Meyer, A. J. Giordano, H. Li, P. Winget, T. Papadopoulos, H. Cheun, J. Kim, M. Fenoll, A. Dindar, W. Haske, E. Najafabadi, T. M. Khan, H. Sojoudi, S. Barlow, S. Graham, J.-L. Brédas, S. R. Marder, A. Kahn, B. Kippelen, A universal 
method to produce low-work function electrodes for organic electronics, Science 336 (2012) 327332.

11. T.-H. Lai, S.-W. Tsang, J. R. Manders, S. Chen, F. So, Properties of interlayer for organic photovoltaics, Mater. Today 16 (2013) 424-432.

12. Zhao, W.; Li, S.; Yao, H.; Zhang, S.; Zhang, Y.; Yang, B.; Hou, J. Molecular optimization enables over 13\% efficiency in organic solar cells, J. Am. Chem. Soc. 139 (2017) 7148-7151.

13. Vasilopoulou, M.; Polydorou, E.; Douvas, A. M.; Palilis, L. C.; Kennou, S.; Argitis, P. Annealingfree highly crystalline solution-processed molecular metal oxides for efficient single-junction and tandem polymer solar cells, Energy Environm. Sci. 8 (2015) 2448-2463.

14. C. V. Hoven, R. Yang, A. Garcia, V. Crockett, A. J. Heeger, G. C. Bazan, T.-Q. Nguyen, Electron injection into organic semiconductor devices from high work function cathodes, Proc. Natl. Acad. Sci. U.S.A 105 (2018) 12730-12735.

15. C. Murawski, K. Leo, M. Gather, Efficiency roll-off in organic light-emitting diodes, Adv. Mater. 25 (2013) 6801-6827.

16. B. R. Lee, S. Lee, J. H. Park, E. D. Jung, J. C. Yu, Y. S. Nam, J. Heo, J.-Y. Kim, B.-Su Kim, M. H. Song, Amine-based interfacial molecules for inverted polymer-based optoelectronic devices, Adv. Mater. 27 (2015) 3553-3559.

17. C. Hoven, R. Yang, A. Garcia, A. J. Heeger, T.-Q. Nguyen, G. C. Bazan, Ion motion in conjugated polyelectrolyte electron transporting layers, J. Am. Chem. Soc. 129 (2007) 10976-10977.

18. T. Kim, M. Suh, S. J. Kwon, T. H. Lee, J. E. Kim, Y. J. Lee, J. H. Kim, M. Hong, K. S. Suh, Poly(3,4ethylenedioxythiophene) derived from poly(ionic liquid) for the use as hole-injecting material in organic light-emitting diodes. Macromol. Rapid Comm. 30 (2009)1477-1482.

19. L. P. Lu, D. Kabra, R. H. Friend, Barium hydroxide as an interlayer between zinc oxide and a luminescent conjugated polymer for light-emitting diodes, Adv. Funct. Mater. 22 (2012) 41654171. 
20. Lange, I. et al. I. Lange, S. Reiter, M. Pätzel, A. Zykov, A. Nefedov, J. Hildebrandt, S. Hecht, S. Kowarik. C. Wöll, G. Heimel, D. Neher, Tuning the work function of polar zinc oxide surfaces using modified phosphonic acid self-assembled monolayers, Adv. Funct. Mater. 24 (2014) 70147024.

21. M. Liu, M. B. Johnston, H. J. Snaith, Efficient planar heterojunction perovskite solar cells by vapour deposition, Nature 501 (2013) 395-398.

22. M. Abuhelaiqa, S. Paek, Y. Lee, K. T. Cho, S. Heo, E. Oveisi, A. J. Huckaba, H. Kanda, H. Kim, Y. Zhang, R. Humphry-Baker, S. Kinge, A. M. Asiri, M. K. Nazeeruddin, Stable perovskite solar cells using tin acetylacetonate based electron transporting layers, Energy Environ. Sci. 12 (2019) 1910-1917.

23. A. Fakharuddin, L. Schmidt-Mende, G. Garcia-Belmonte, R. Jose, I. Mora-Sero, Interfaces in perovskite solar cells, Adv. Energy Mater. 7 (2017) 1700623.

24. S. S. Shin, E. J. Yeom, W. S. Yang, S. Hur, M. G. Kim, J. Im, J. Seo, J. H. Noh, S. I. Seok, Colloidally prepared La-doped $\mathrm{BaSnO}_{3}$ electrodes for efficient, photostable perovskite solar cells, Science 356 (2017) 167-171.

25. A. Pérez-Tomas, H. Xie, Z. Wang, H.-S. Kim, I. Shirley, S.-H. Turren-Cruz, A. Morales-Melgares, B. Saliba, D. Tanenbaum, M. Saliba, S. M. Zakeeruddin, M. Gratzel, A. Hagfeldt, M. Lira-Cantu, $\mathrm{PbZrTiO}_{3}$ ferroelectric oxide as an electron extraction material for stable halide perovskite solar cells, Sustainable Energy Fuels 3 (2019) 382-389.

26. X. Yu, T. J. Marks, A. Facchetti, Metal oxides for optoelectronic applications, Nat. Mater. 15 (2016) 383-396.

27. C. Li, T. Wang, Z. Luo, D. Zhang, J. Gong, Transparent ALD-grown $\mathrm{Ta}_{2} \mathrm{O}_{5}$ protective layer for highly stable ZnO photoelectrode in solar water splitting, Chem. Commun. 51 (2015) 7290-7293.

28. Y. Wan, S. K. Karuturi, C. Samundsett, J. Bullock, M. Hettick, D. Yan, J. Peng, P. R. Narangari, S. Mokkapati, H. H. Tan, C. Jagadish, A. Javey, A. Cuevas, Tantalum oxide electron-selective 
heterocontacts for silicon photovoltaics and photoelectrochemical water reduction, ACS Energy Lett. 31 (2018) 125-131.

29. R. Nakamura, T. Tanaka, Y. Nakato, Oxygen photoevolution on a tantalum oxynitride photocatalyst under visible-light irradiation: How does water photooxidation proceed on a metal-oxynitride Surface? J. Phys. Chem. B 109 (2005) 8920-8927.

30. H. Tu, L. Xu, F. Mou, J. Guan. Single crystalline tantalum oxychloride microcubes: controllable synthesis, formation mechanism and enhanced photocatalytic hydrogen production activity, Chem. Commun. 51 (2015) 12455-12458.

31. X. Yue, Y. Jin, P. K. Shen, Highly stable and efficient non-precious metal electrocatalysts of tantalum dioxyfluoride used for the oxygen evolution reaction, J. Mater. Chem. A 5 (2017) 82878291.

32. X. Yue, C. He, C. Zhong, Y. Chen, S. P. Jiang, P. K. Shen, Fluorine-doped and partially oxidized tantalum carbides as nonprecious metal electrocatalysts for methanol oxidation reaction in acidic media. Adv. Mater. 28 (2016) 2163-.2169.

33. D. M. Antonelli, J. Y. Ying, Synthesis and characterization of hexagonally packed mesoporous tantalum oxide molecular sieves, Chem. Mater. 8 (1996) 874-881.

34. L. Shen, X. Zhou, X. Zhang, Y. Zhang, Y. Liu, W. Wang, W. Si, X. Dong, Carbon-intercalated $\mathrm{Ti}_{3} \mathrm{C}_{2} \mathrm{~T}_{\mathrm{x}} \mathrm{MXene}$ for high performance electrochemical energy storage, J. Mater. Chem. A 6 (2018) $23513-23520$

35. S. Zhang, Y. Qin, J. Zhu, J. Hou, Over 14\% Efficiency in Polymer Solar Cells Enabled by a Chlorinated Polymer Donor, Adv. Mater. 30 (2018) 1800613.

36. S. Grimme, J. Antony, S. Ehrlich, H. Krieg, A consistent and accurate ab initio parametrization of density functional dispersion correction (DFT-D) for the 94 elements H-Pu, J. Chem. Phys. 132, (2010) 154104. 
37. E. Polydorou, I. Sakellis, A. Soultati, A. Kaltzoglou, T. A. Papadopoulos, J. Briscoe, D. Tsikritzis, M. Fakis, L. C. Palilis, S. Kennou, P. Argitis, P. Falaras, D. Davazoglou, M. Vasilopoulou, Avoiding Ambient Air and Light Induced Degradation in High-Efficiency Polymer Solar Cells by the Use of Hydrogen-Doped Zinc Oxide as Electron Extraction Material, Nano Energy 34 (2017) $500-514$.

38. K. Y. Yiang, W. J. Yoo, Investigation of electrical conduction in carbon-doped silicon oxide using a voltage ramp method, Appl. Phys. Lett. 83 (2003) 524-526.

39. Y. Abbas, Y.-R. Jeon, A. S. Sokolov, S. Kim, B. Ku, C. Choi, Compliance-free, digital SET and analog RESET synaptic characteristics of sub-tantalum oxide based neuromorphic device, Sci. Rep. 8 (2018) 1228.

40. Y. Xin, P. K. Shen, Tantalum carbide doped by fluorine as non-precious metal anodic electrocatalyst superior to Pt/C for glycerol-oxidation, Electrochim. Acta 227 (2017) 267-274.

41. R. Simpson, R. G. White, J. F. Watts, M. A. Baker, XPS investigation of monatomic and cluster argon ion sputtering of tantalum pentoxide, Appl. Surf. Sci. 405 (2017) 79-87.

42. T. Horikawa, N. Sakao, T. Sekida, J. Hayashi, D. D. Doc, M. Katoh, Preparation of nitrogen-doped porous carbon by ammonia gas treatment and the effects of $\mathrm{N}$-doping on water adsorption, Carbon 50 (2012) 1833-1842.

43. A. Agulyansky, The Chemistry of Tantalum and Niobium Fluoride Compounds, Elsevier, Boston, 2004, p. 8 .

44. L. K. Frevel, H. W. Rinn, The crystal structure of $\mathrm{NbO}_{2} \mathrm{~F}$ and $\mathrm{TaO}_{2} \mathrm{~F}$, Acta Crystallogr. 9 (1956) $626-627$.

45. V. Gutman, K. H. Jack, The crystal structures of molybdenum trifluoride, $\mathrm{MoF}_{3}$, and tantalum trifluoride, $\mathrm{TaF}_{3}$. Acta Crystallogr. 4 (1951) 244-246.

46. J. C. Biffinger, H. W. Kim, The polar hydrophobicity of fluorinated compounds, ChemBioChem 5 (2004) 622-627. 
47. I. Hodgkinson, Q. h. Wu, J. Hazel, Empirical equations for the principal refractive indices and column angle of obliquely deposited films of tantalum oxide, titanium oxide, and zirconium oxide, Appl. Opt. 37 (1993) 2653-2659.

48. L. Liu, Z. Mei, Y. Hou, H. Liang, A. Azarov, V. Venkatachalapathy, A. Kuznetsov, X. Du, Fluorine doping: a feasible solution to enhancing the conductivity of high-resistance wide bandgap $\mathrm{Mg}_{0.51} \mathrm{Zn}_{0.49} \mathrm{O}$ active components, Sci. Rep. 5 (2015) 15516.

49. G. Henkelman, A. Arnaldsson, H. Jónsson, A fast and robust algorithm for Bader decomposition of charge density, Comput. Mater. Sci. 36 (2006) 354-360.

50. W. Tang, E. Sanville, G. Henkelman, G. A grid-based Bader analysis algorithm without lattice bias, J. Phys. Condens. Matter 21 (2009) 084204.

51. D. G. Georgiadou, L. C. Palilis, M. Vasilopoulou, G. Pistolis, D. Dimotikali, P. Argitis, Effect of triphenylsulfonium triflate addition in wide band-gap polymer light emitting diodes: improved charge injection, transport and electroplex-induced emission tuning, RSC Adv. 2 (2012) 1178611792.

52. J. Zhao, Y. Cai, J.-P. Yang, H.-X. Wei, Y.-H. Deng, Y.-Q. Li, S.-T. Lee, J.-X. Tang, The role of cesium carbonate on the electron injection and transport enhancement in organic layer by admittance spectroscopy. Phys. Lett. 101 (2012) 193303.

53. B. R. Lee, E. D. Jung, J. S. Park, Y. S. Nam, S. H. Min, B.-S. Kim, K.-M. Lee, J.-R. Jeong, R. H. Friend, J.-S. Kim, S. O. Kim, M. H. Song, Highly efficient inverted polymer light-emitting diodes using surface modifications of ZnO layer, Nature Comm. 5 (2014) 4840.

54. M. Sessolo, H. J. Bolink, Hybrid organic-inorganic light-emitting diodes, Adv. Mater. 23 (2011) 1829-1845.

55. K. Vandewal, S. Albrecht, E. T. Hoke, K. R. Graham, J. Widmer, J. D. Douglas, M. Schubert, W. R. Mateker, J. T. Bloking, G. F. Burkhard, A. Sellinger, J. M. J. Fréchet, A. Amassian, M. 
K. Riede, M. D. McGehee, D. Neher, A. Salleo, Efficient charge generation by relaxed chargetransfer states at organic interfaces, Nat. Mater. 13 (2014) 63-68.

56. J. Yuan, Y. Zhang, L. Zhou, G. Zhang, H.-L. Yip, T.-K. Lau, X. Lu, C. Zhu, H. Peng, P. A. Johnson, M. Leclerc, Y. Cao, J. Ulanski, Y. Li, Y. Zou, Single-Junction Organic Solar Cell with over 15\% Efficiency Using Fused-Ring Acceptor with Electron-Deficient Core, Joule 3 (2019) 1140-1151. 


\section{Figures}

(a)

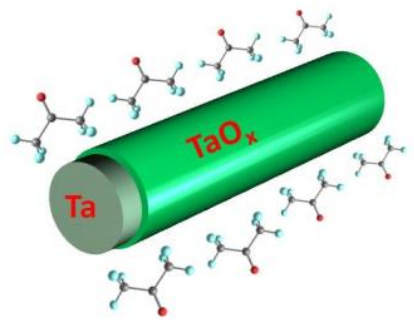

(d)

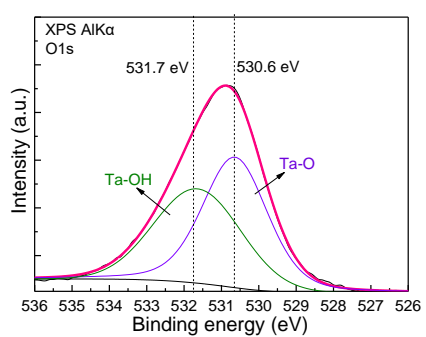

(b)

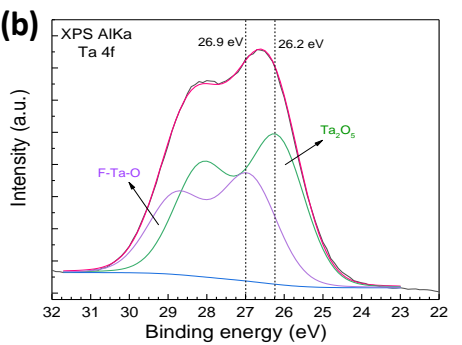

(e)

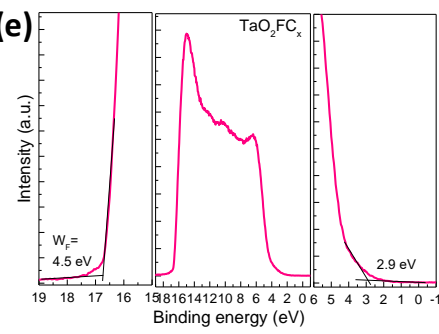

(c)

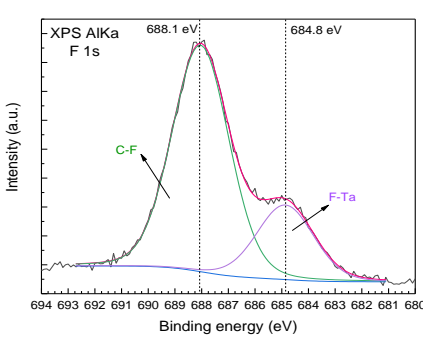

(f)

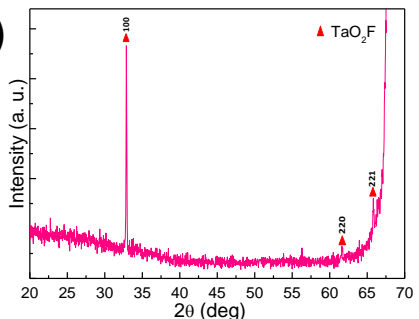

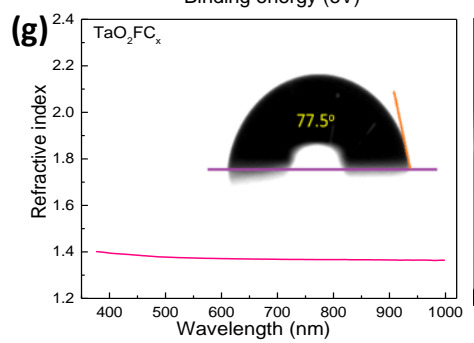
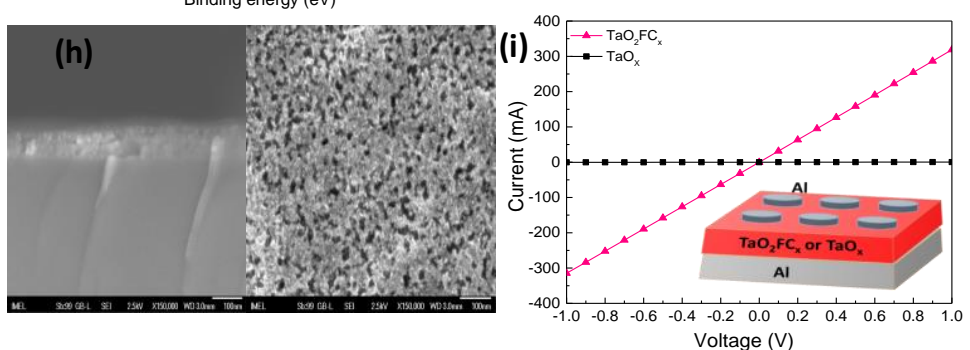

Figure 1 (a) Schematic illustration of the procedure for the synthesis of $\mathrm{TaO}_{2} \mathrm{FC}_{\mathrm{x}}$. (b) $\mathrm{Ta} 4 \mathrm{f}$, (c) $\mathrm{F} 1 \mathrm{~s}$ and (d) O 1s XPS peaks of the carbon-doped tantalum dioxylfluoride film deposited on ITO substrate. $€$ UPS spectrum of the same film. (f) X-ray diffraction pattern, (g) measured refractive index and (h) SEM topography of the $\mathrm{TaO}_{2} \mathrm{FC}_{\mathrm{x}}$ film deposited on silicon substrate. The water contact angle measurement of this film is shown as inset in Fig. 1g. (i) Current-voltage characteristics of the device with a structure $\mathrm{Al} / \mathrm{TaO}_{2} \mathrm{FC}_{\mathrm{x}} / \mathrm{Al}$ (shown as inset). The respected characteristics of the structure $\mathrm{Al} / \mathrm{TaO}_{\mathrm{x}} / \mathrm{Al}$ is also shown for comparison. 
(a)
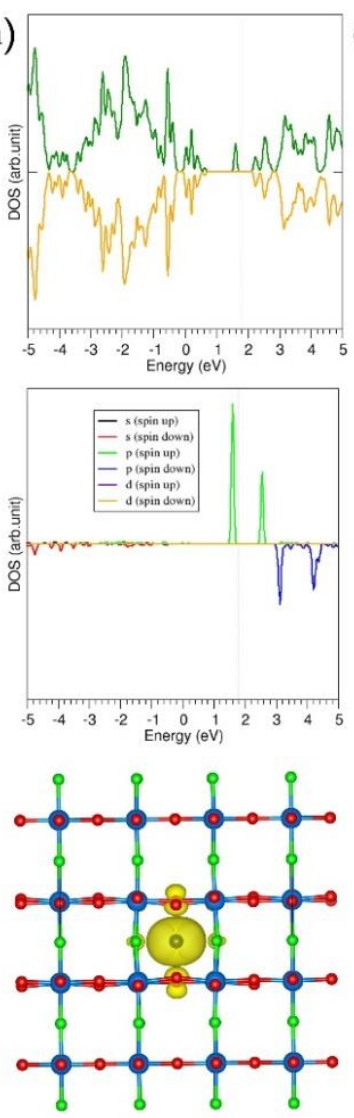

(b)

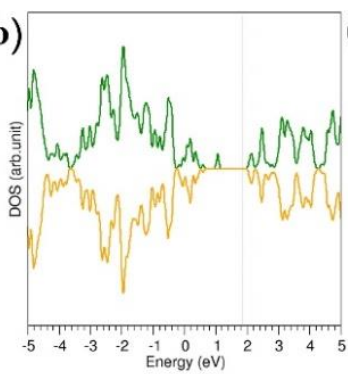

(c)
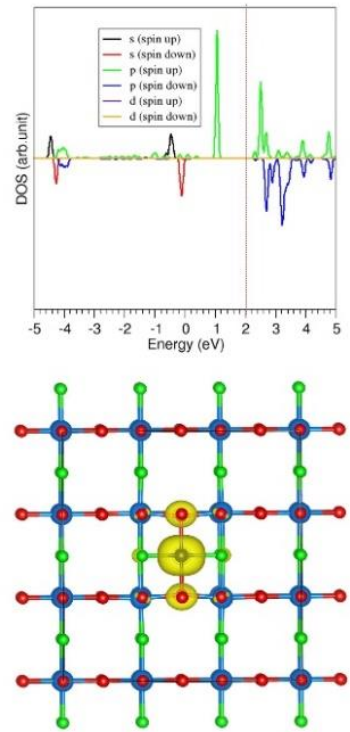
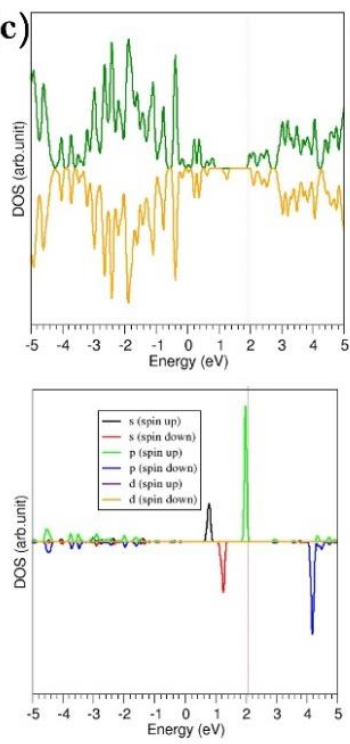

(d)
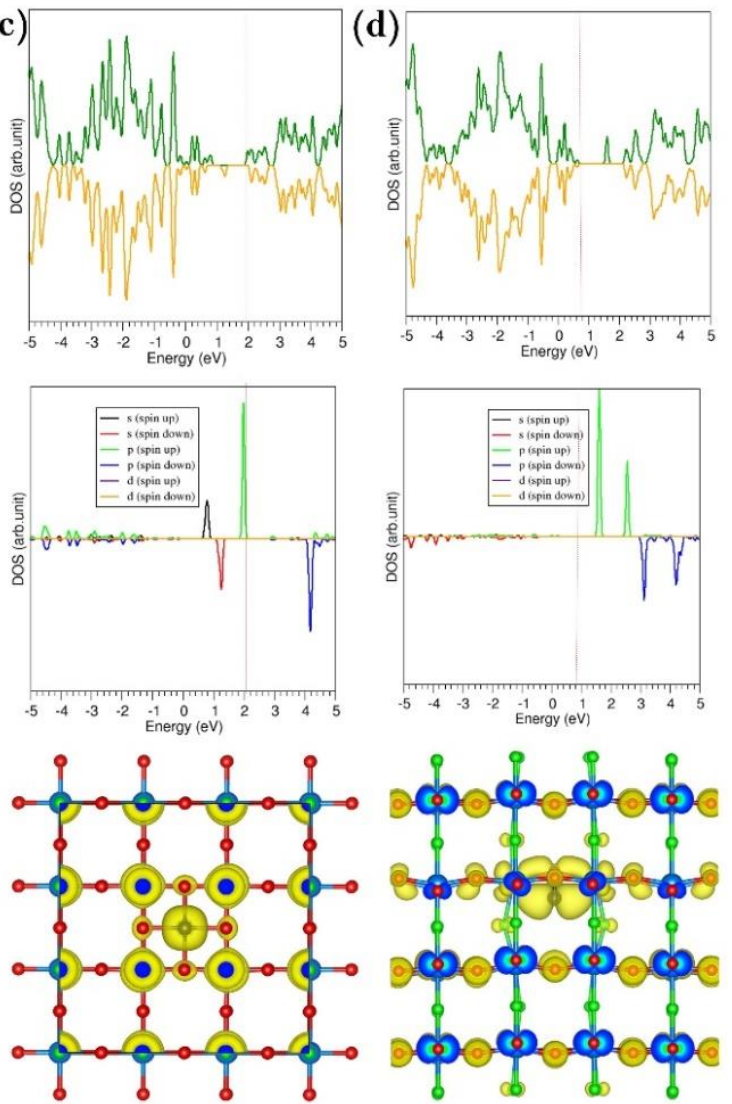

Figure 2 Total DOS plots, Atomic DOS for C and constant charge density plots associated with $\mathrm{C}$ in the relaxed configurations. Plots a, b, c, and d, correspond to the configurations $\mathrm{P}, \mathrm{Q}, \mathrm{R}$ and $\mathrm{S}$ respectively. 

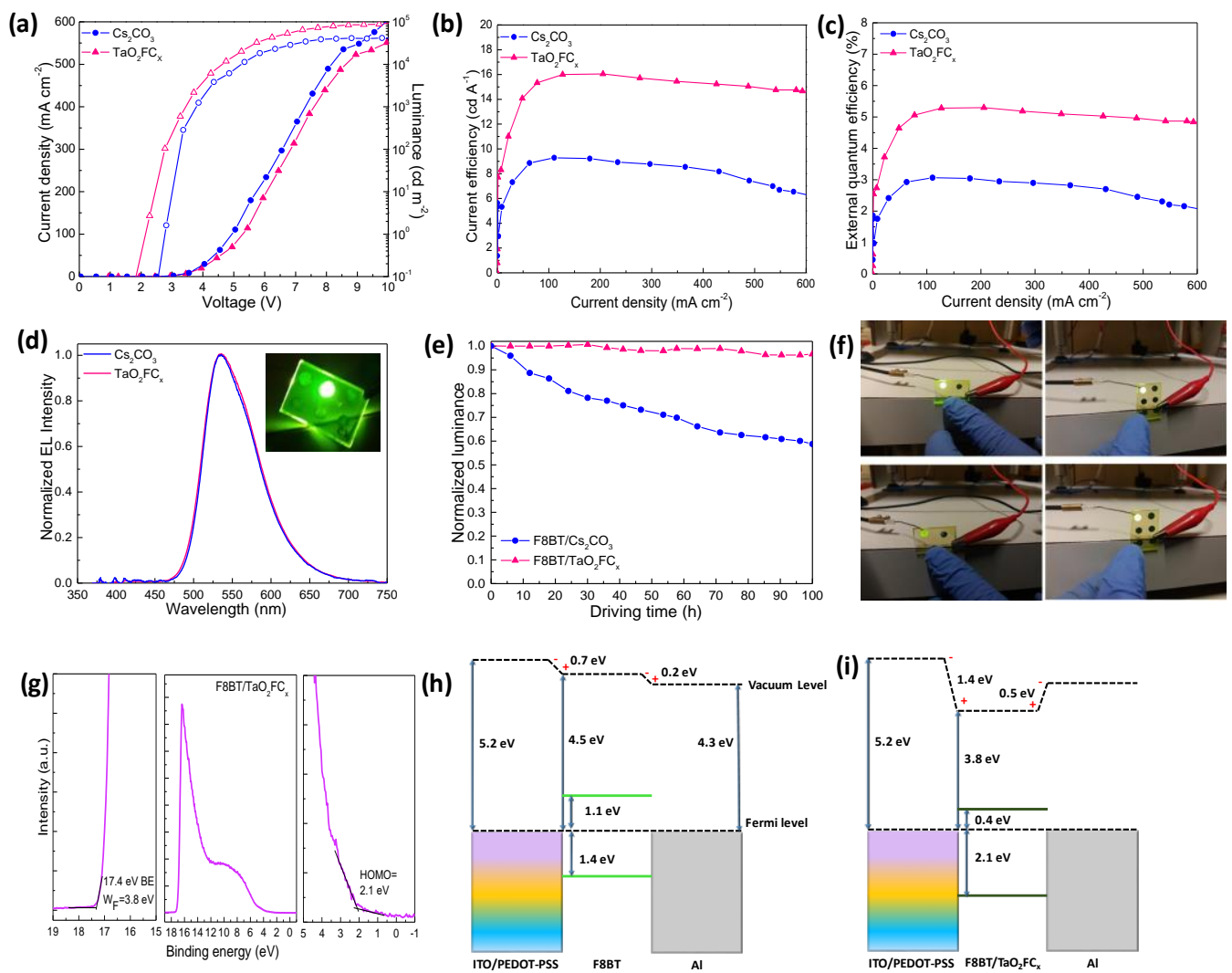

Figure 3 (a) Current density and luminance versus voltage ( $\mathrm{J}-\mathrm{V}-\mathrm{L}$ ) characteristics, (b) current efficiency and (c) external EL quantum efficiency versus current density of the F8BT-based OLEDs using either $\mathrm{Ca}_{2} \mathrm{CO}_{3}$ or $\mathrm{TaO}_{2} \mathrm{FC}_{\mathrm{x}}$ films as the electron transport layer (external EL quantum efficiency

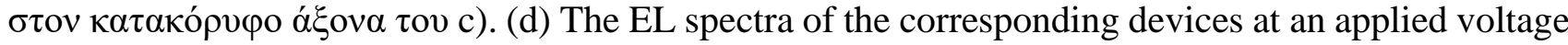
of 6V. (e) Lifetime measurements: Normalized luminance versus driving time of the F8BT-based OLEDs at a constant current density of $15 \mathrm{~mA} \mathrm{~cm}^{-2}$. (f) Photographs of the working OLEDs having $\mathrm{Ca}_{2} \mathrm{CO}_{3}$ (left) and $\mathrm{TaO}_{2} \mathrm{FC}_{\mathrm{x}}$ (right) as the electron selective contacts at $0 \mathrm{~h}$ (up) and $100 \mathrm{~h}$ (down) of constant operation. (g) UPS spectra (left: the high binding energy cut-off, middle: an expanded view and right: the near Fermi level region) of an F8BT film deposited on PEDOT-PSS on ITO/glass substrate after the deposition of the $\mathrm{TaO}_{2} \mathrm{FC}_{\mathrm{x}}$ film. The corresponding energy level diagram of the OLED devices with the configuration (h) ITO/PEDOT-PSS/F8BT/Al and (i) ITO/PEDOT$\mathrm{PSS} / \mathrm{F} 8 \mathrm{BT} / \mathrm{TaO}_{2} \mathrm{FC}_{\mathrm{x}} / \mathrm{Al}$, assuming a constant Fermi level at thermodynamic equilibrium. 
(a)

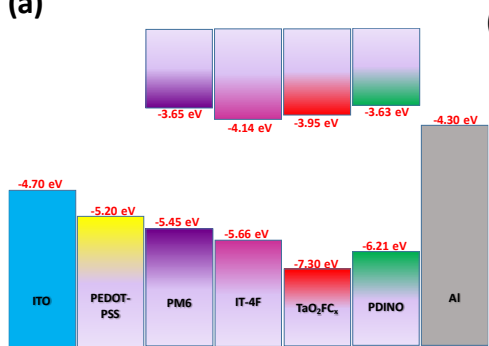

(d)

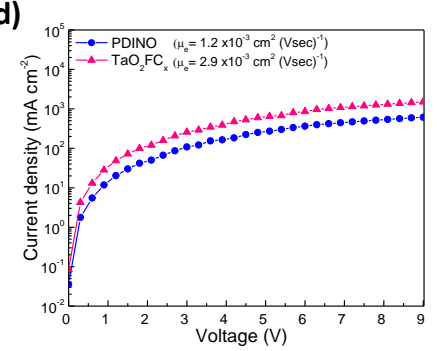

(g)

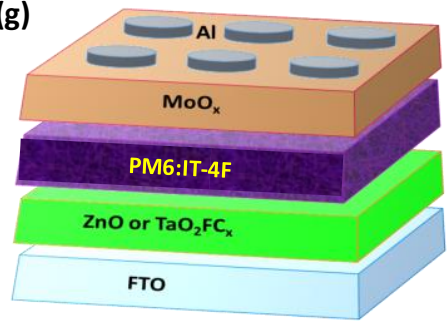

(b)

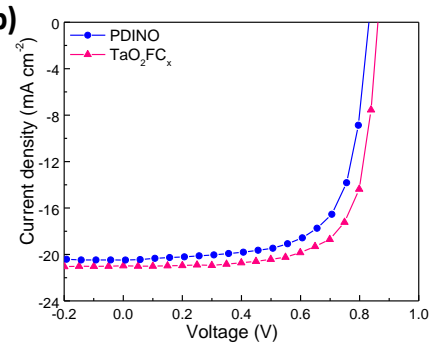

(e)

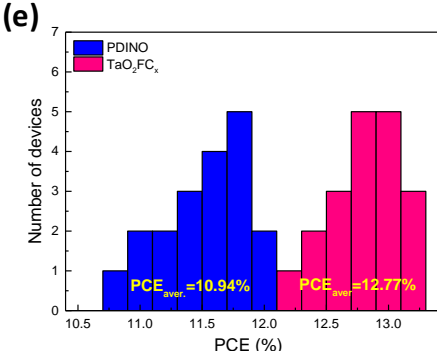

(h)

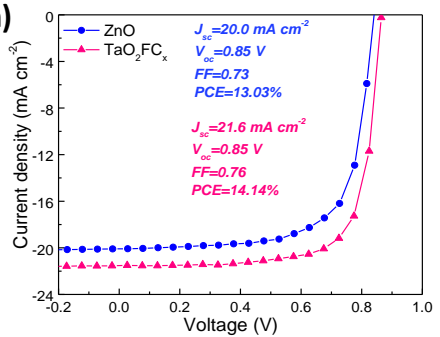

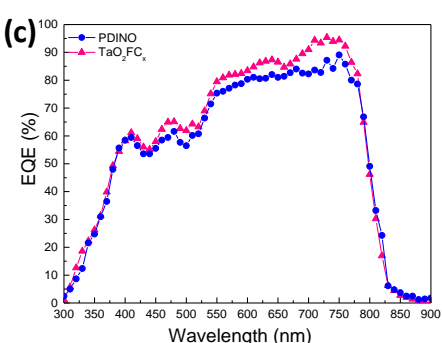

(f)
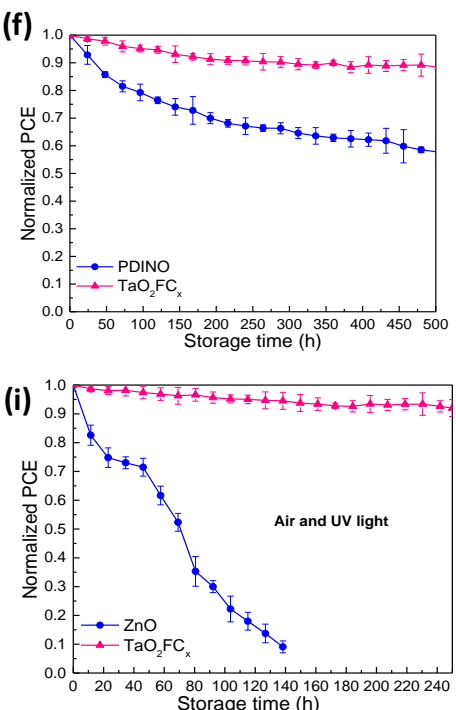

Figure 4 (a) The energy levels of the materials used in the PM6:IT-4F OSCs (before contact, considering vacuum level alignment). (b) J-V characteristic curves taken under 1.5 AM illumination and (c) EQE spectra of PM6:IT-4F based OSCs. (d) The J-V characteristics of electron-only devices, (e) the PCE statistics and (f) variation of PCE versus storage time of unencapsulated devices. (g) The inverted OSC architecture, (h) J-V under 1.5 AM illumination of the devices shown in (g) and (i) The variation of PCE of unencapsulated inverted devices versus time in air under UV illumination. 